Zeitschrift für Nationalökonomie 33 (1973), 213-234

(C) by Springer-Verlag 1973

\title{
Exhaustion and Technological Development: A Macro-Dynamic Policy Model*
}

\author{
By \\ Jan Tinbergen, Den Haag
}

(Received September 17, 1973)

\section{Scope of this Essay}

The main components of the problem complex posed by the Club of Rome are what the joint effect will be, and how it can be influenced, of (i) population growth, (ii) increase of pollution, (iii) the exhaustion of material resources and (iv) technological development. From the discussions of the last few years my main impressions are that policies to curb population growth and pollution are within reach, even though formidable obstacles will have to be faced. Put in oversimplified terms, the population explosion begins to be seen by a rapidly increasing number of people as a danger; various means to put a break on it have been developed and there is a group of countries where the effect of their use begins to be visible. Also a number of expert calculations on the means needed to keep pollution under control suggest that these are of the order of 4 per cent of national income for some developed countries; a figure not too deconcerting [15].

Quite a few of the critics of the Meadows Report [11] have come to the conclusion, which I share, that the weaker parts of the Meadows model are those dealing with the phenomenon of exhaustion of material resources and the possible counterforces of technological development. In order to insert these two elements into a detailed model one must first understand the nature of the effects of these two phenomena and, if possible, have a crude idea of the orders of magnitude involved. This essay is an attempt to do so with the

* I am indebted to Professors O. Rademaker and H. Linnemann for helpful comments on an earlier draft of this article. Of course the responsibility for the present text is mine. 
aid of simple methods of analysis and some pieces of information now available. This attempt may be called, if one likes, an attempt to formulate a very crude macro-dynamic model for the relevant period (of the order of a century and beyond); a model directed at planning the policies needed to avoid disaster. While a comprehensive model with such an ambitious goal will have to give considerable attention to social policies (especially those of population, education and income distribution), these elements are not dealt with here, but elsewhere. Rather the emphasis in this essay will be on the programmes of scientific and technological research, necessary to reach the aim of maintaining a desirable level of total consumption and hence production, which also will be of considerable importance.

The main feature of this very crude model will be that, if left to present policies, the tendency of production will be first to go on rising, perhaps for quite some time, but unavoidably later on will have a falling branch, giving the picture of a bell-shaped development over time. Superimposed on it will be the desirable effect of technological development tending to maintain some "decent" level of consumption per capita. The nature of the technological research needed for this purpose and some of its components will be the main unknowns, and the answer is hoped to be of at least some relevance to future research programmes in these fields.

\section{Starting Points and Main Structures of the Models Considered}

The main model is going to be presented in three alternative forms. Moreover, one aspect of the problem is considered in some more detail. This is why, in the title of this section, we speak of "models", in plural.

A common feature of the alternatives is the distinction of two types of resources or produtcion factors, and based on it the distinction between two types of activities (or industries in the widest sense) and products, for each of these three phenomena to be called exhaustibles and non-exhaustibles. Exhaustible resources are materials supplied by the earth and the atmosphere; characteristically they are available in finite quantities, sometimes called reserves. As a rule these reserves are larger than the "known reserves", but a day will come when all reserves are known. Non-exhaustibles are such production factors as solar radiation energy, up to the level of total radiation received by the earth system, and contributions by the human mind, sometimes indicated as human capital (for reasons which do not matter here), or as technological progress or inventions. Activities and their products will be called exhaustible, when the 
larger part (for instance expressed in value terms) of their inputs consists of exhaustible resources. The remaining ones are classified as non-exhaustible. Exhaustible activities' production will be written as $\dot{y}$ per annum, implying that the accumulated total since the beginning of their production is written as $y$; in addition, the stock available at the beginning will be written as $A$. The annual production of non-exhaustibles will be written as $x$ and total annual production as $z$; hence $z=x+\dot{y}$.

Exhaustible activities are almost the same as primary activities (agriculture and mining), but we will add manufacturing industries using large inputs of mining or agricultural products, such as metallurgy, public utilities, and food processing. Of course a portion of agriculture, namely the part that fits into a closed agricultural-biological cycle or can be brought into it, is non-exhaustible. The increasing use of fertilizer, pesticides and so on tends to reduce, however, the non-exhaustible part of agriculture to a small portion only. Exhaustible activities are also close to what nowadays are indicated as "process industries", provided we include the exhaustible part of agriculture and mining. Generally these activities leave a lot to be done by nature, within a frame set by human activity. Natural processes involved belong to the biological, chemical and physical type and man leaves, it to cells molecules and atoms, or their constituent parts, to produce the desired material output. In a way their technology leaves a considerable element of "laissez faire" to the elements mentioned, in contradistinction to non-process industries. Although technologists do not lump together the other productive activities into one single category, I wonder whether one could not characterize them by the phrase "constructive", meant to emphasize the conscious and direct human activity to shape the desired product by putting the parts together. Whereas the phrase "process industry" has already got some official status, the few authors I came across who also describe the other types of industries, prefer to keep apart engineering, textiles and "other" (Pratten [12]) or engineering, tools and apparatuses, building and research activities - leaving no place for textiles, or printing - (van Dixhoorn [16]). A full discussion of this categorization will not be given here; but an indication of it seems useful when it comes to differences in production functions which we will discuss later (cf. Section 5). Already now I want to point out that not only manufacturing industries, but all productive activities must be included, also what we in the West call services. And whatever the similarities with the two types of distinction (primary vs non-primary and process or non-process activities), for our purpose the essential distinction is between production of exhaustibles and non-exhaustibles. 
For the exhaustibles among the resources, and hence approximately also among products, as already observed, there exists some finite stock $A$ available in or around the earth, which sets a limit to accumulated production over time. At any time $t$ a quantity of $y_{t}$ has already been used and net production per unit of time may be written as $\dot{y}_{t} \equiv \frac{d y}{d t}$. In a first approach I will consider $A$ as given and known. It is characteristic for $\dot{y}$ to have an ascending branch, followed by a descending one; during the latter $\dot{y}$ tends to zero, but need not reach this value in a finite time period. Total production $z=x+\dot{y}$ is what matters for the satisfaction of human needs and we will consider a few alternative "target developments" for $z$; among them maintenance, after an initial period of growth, of the value attained or maintenance of its value per capita, with alternative assumptions for the development of population.

Whereas the production function of $x$ will be assumed to belong to the types currently used by econometrists - Cobb-Douglas, CES or fixed-ratio-between-production-factors - there are good reasons to work with different types of production functions for $\dot{y}$. Here I propose to use the well-known function:

$$
\dot{y}=\delta(A-y) y
$$

leading to the development over time for $y$, cumulated past production:

$$
y=\frac{A}{1+e^{-\delta A\left(t-t_{0}\right)}}
$$

representing the well-known logistic curve and for $\dot{y}$ :

$$
\dot{y}=\frac{\delta A^{2} e^{-\delta A\left(t-t_{0}\right)}}{\left\{1+e^{-\delta A\left(t-t_{0}\right)}\right\}^{2}}
$$

yielding a bell-shaped curve, as desired.

For non-consumable material resources cumulated past production is equal to the stock available, that is, part of the community's capital stock. For consumer goods among the exhaustibles the stock available is the cumulated value over time of net production, that is, production minus consumption. For these materials $A$ is shrinking over time by the amount of cumulated consumption (cf. Section 3).

The usual philosophy behind (2.1) is that the probability that a unit of $A-y$ (the stock of resources available, but not yet used) meets a unit of $y$ is proportional to the "concentration" (that is the quantity available) of each of the elements necessary to create a unit of the 
desired product. That philosophy is a special case of Guldberg and Wa a ge's Law of mass action, known in chemistry. So far it has been used, first of all, to explain the development of the size of populations of living beings to which a given flow $A$ of food is available per time unit. It has also been used by market analysis to explain the development over time of the stock of a durable new product, such as telephones, radios or television sets. Here the philosophy can be specified to say that the probability of an additional set to be sold depends, in fact, on the number of sets $y$ already sold (demonstration effect) and the number of potential new buyers $A-y$, where $A$ represents the number of people who wish or can afford to have a set. Since in the process industries production often means the meeting of two elements (seed and nitrients, cattle and food, nitrogen and oxygen to produce NO, in chemical symbols; or more generally, machines and raw materials) there is something to be said in favour of production function (2.1).

In order to meet the possible objection that the meeting of a unit of raw material and a unit of production capacity is not left to chance, as our last example seems to imply, an alternative setup will be offered here. Considering the history over time of manufacturing, for instance, we may say that in the early phases of industrialization it was the productive capacity or accumulated previous investments $y$ that determined production $\dot{y}$ by, say, an equation:

$$
\dot{y}=\delta^{\prime} y .
$$

In the later phases, when the remaining stock $A-y$ of not yet used exhaustible resources begins to be known as a bottle neck, it will be that stock which determines production $\dot{y}$, maybe according to an equation:

$$
\dot{y}=\delta^{\prime \prime}(A-y) .
$$

Here we use limitative production functions instead of substitutive. For the early part of industrial production we obtain, from $(2.1)^{\prime}$ :

and for the later part:

$$
y=\bar{y} e^{\delta t}
$$

$$
y=A-\overline{\bar{y}} e^{-\delta^{\prime \prime} t}
$$

meaning that the first part is an exponential curve with an initial value $\bar{y}$ and a rate of growth $\delta^{\prime}$, whereas the later part shows an exponential development of $A-y$ with a rate of growth of $-\delta^{\prime \prime}$ and and initial value $A-\overline{\bar{y}}$. If we assume, in addition, that only limitative production functions are describing the actual behaviour of pro- 
ducers, function $\left(2.1^{\prime}\right)$ must exist until the value of $y_{0}$ is reached where function $\left(2.1^{\prime \prime}\right)$ starts to be valid, the change must take place for the value of $y_{0}$ which satisfies both $\left(2.2^{\prime}\right)$ and $\left(2.2^{\prime \prime}\right)$ :

$$
y_{0}=\bar{y} e^{\delta^{\prime} t}=A-\overline{\bar{y}} e^{\delta^{\prime \prime} t}
$$

In this equation the unknowns are $t$ and $\overline{\bar{y}}$. Indicating the value of $t$ by $t_{0}$ we have as the second condition to be fulfilled, that also $\dot{y}$ derived from $\left(2.1^{\prime}\right)$ must be equal to $\dot{y}$ derived from $\left(2.1^{\prime \prime}\right)$, or

$$
\dot{y}_{0}=\delta^{\prime} y_{0}=\delta^{\prime \prime}\left(A-y_{0}\right)
$$

from which $y_{0}$ can be determined:

$$
y_{0}=\frac{\delta^{\prime \prime} A}{\delta^{\prime}+\delta^{\prime \prime}}
$$

The time $t_{0}$ at which this value of $y$ is attained, can be determined from

$$
y_{0}=\bar{y} e^{\delta^{\prime} t_{0}}
$$

and finally we may express $\overline{\bar{y}}=y_{0}$ directly in terms of $t_{0}$ by using $\left(2.2^{\prime \prime \prime}\right)$ :

$$
y_{0}=\frac{A}{1+e^{-\delta^{\prime \prime}} t_{0}}
$$

The development over time of $y$ and $\dot{y}$ now obtained has much in common with the logistic curve; we will refer to it as the quasilogistic curve. An advantage of the quasi-logistic curve is that the rate of negative) growth $\delta^{\prime \prime}$ in the second part can now be seen as a policy parameter and need not be equal to the rate of growth $\delta^{\prime}$ in the first part, which is determined by some sort of output-capitallike concept.

We will also use, as an alternative, a different, but similar formula (cf. Section 4), in order to meet the objection that function (2.1) is of degree 2 in the factors of production. If we think of the all-important commodity steel, $y$ may be said to represent the economy's capital stock, whereas $\delta(A-y)$ may be thought of as the input of raw materials, because $A-y$ is equal to the available volume of potential input of iron ore, expressed in units of steel. Some other questions arising around this approach will be discussed in Sections 4-7.

To begin with, we will assume that $A$ is given and known. But a simple generalization of (2.1) consists of the assumption that over time $A$ is growing: known reserves of all material resources have been growing so far. There is a limit to this growth - the point made by 
the title of the Meadows Report - , however, and this induced me to discuss our problem in three phases, to be called (1), (2) and (3). The hope behind such a discussion is that these will be successive time periods also. Phase (1) is the past, (2) and (3) are possible future phases. Phase (1) will be used to derive some relevant coefficients of our models. In phase (2) the further rise in $A$ will be assumed and dealt with in two different approaches. The objection that one cannot treat $A$ as a variable and yet apply the solutions (2.2) and (2.3) can be met by the assumption that the changes in $A$ are slow, leading to a succession of near-equilibria, as in comparative statics in economics or adiabatic changes in physics. Finally, in phase (3) $A$ will be considered constant, representing the real limit to $y$ and $\dot{y}$ will then fall accordingly; if $y$ comes close to $A$ the fall in $\dot{y}$ will practically be at a constant rate, the same as in the beginning of the logistic curve. This approach might be seen, I hope, as another chapter of what B a u mol once [1] baptized the "magnificent dynamics" of 19-th century economists.

\section{Phase (2) of the Model}

We may think of phase (2) as situated before and in the neighbourhood of the maximum volume of production $\dot{y}$ of exhaustibles and as some postponement of the threat that either income per capita begins to remain constant or even starts falling. The essence of the phase is that the production of exhaustibles can still be increased as a consequence of an increase in available stock or "known reserves" $A-y$, but only "at a price", namely the price increase needed to induce producers of exhaustibles to exploit deposits of less quality or less easy to reach. We already stated that for consumer goods among the exhaustibles $A$ already falls as a consequence of consumption. Here an even larger increase in known reserves will be needed.

Let the originally planned real rate of increase of total production at constant prices be $b$ per annum. By "originally planned" we mean the plan before the increased scarcity of the exhaustible resources was taken into account. Correspondingly the rate of increase of demand for exhaustibles will be $\varepsilon b$, if $\varepsilon$ is the income elasticity of demand for them. This increase will, however, only be attained if a price rise of exhaustibles in terms of all goods occurs sufficient to raise their supply by $\varepsilon b$. Let the elasticity of supply with regard to price be $\eta$; without a general price rise the price rise of exhaustibles needed to induce an increase in supply will be $\varepsilon b / \eta$; if, in addition, a general price rise $\pi$ occurs, the price rise needed for exhaustibles will be $\varepsilon b / \eta+\pi$. Assuming that the portion of total income spent on 
exhaustibles is $\alpha$, the general price rise $\pi$ must be equal to $\alpha(\varepsilon b / \eta+\pi)$, from which we find:

$$
\pi=\frac{\alpha \varepsilon b}{(1-\alpha) \eta}
$$

This implies that real income is not growing by $b$, but by

$$
b-\pi=b\left\{1-\frac{\alpha \varepsilon}{(1-\alpha) \eta}\right\} \text {. }
$$

The danger zone will be reached if this figure approaches the rate of population increase $p$.

Reasons for the danger zone being reached may be, first of all, a fall in $b$, which we are going to discuss in Section 4 . In addition, other reasons may be a fall in $\eta$ or an insufficient fall in $p$. The fraction $\frac{\alpha \varepsilon}{(1-\alpha) \eta}$ in the expression for the real income growth rate may be called the income loss due to increased scarcity of material goods. Crude estimates for to-day yield the values $\varepsilon=1, \alpha=0.25$ and $\eta=2.5$; the fraction then becomes 0.13 . Assuming that a population increase of 1 per cent can be attained around the year 2000 and that $b=3$ per cent and $\alpha=0,25$, the danger spot

$$
b\left\{1-\frac{\alpha \varepsilon}{(1-\alpha) \eta}\right\}=p
$$

would be reached when $\varepsilon=2 \eta$ or $\eta=1 /{ }_{2} \varepsilon$. For the moment we are far from that spot; but for $p=2$, a figure clearly lower than the present rate of population increase, the fall of income per capita would be reached already for $\eta=\varepsilon$. There are examples of exhaustibles for which this value already applies. More details will be discussed in Section 8.

The simple analysis just shown can easily be combined with our main model or with alternatives for it. We are now proceeding to this main part of our model.

\section{Phase (3) of the Model: One Exhaustible Good}

As already briefly set out in Section 2, the main alternative of our complete model is based on the production function (2.1), combining in it a production function and a simple dynamic assumption which as a rule, in most models, is expressed in a separate equation, expressing investments as some function of income. The approach followed here was illustrated, in order to make it look plausible, by interpreting $y$ as the production of steel, the backbone of most pro- 
Table I. Values of $t_{0}$ and the Corresponding Maximum $\dot{y}_{0}$ for Various Values of $\gamma A$ (known stock) and Initial Values of $y(\bar{y}) *$

\begin{tabular}{|c|c|c|c|c|c|c|c|c|}
\hline \multicolumn{3}{|c|}{ Values of $\gamma A$} & \multicolumn{3}{|c|}{ Values of $t_{0}$} & \multicolumn{3}{|c|}{ Values of $\dot{y}_{0}(\max )$} \\
\hline $\bar{y}=30$ & $\bar{y}=20$ & $\bar{y}=10$ & $\bar{y}=30$ & $\bar{y}=20$ & $\vec{y}=10$ & $\bar{y}=30$ & $\bar{y}=20$ & $\bar{y}=10$ \\
\hline 90 & 60 & 30 & 13.8 & 9.2 & 4.6 & 1.125 & 1.125 & 1.125 \\
\hline 120 & 80 & 40 & 24.1 & 16.1 & 8.1 & 1.33 & 1.33 & 1.33 \\
\hline 150 & 100 & 50 & 33.1 & 22.1 & 11.0 & 1.56 & 1.56 & 1.56 \\
\hline 180 & 120 & 60 & 40.0 & 26.7 & 13.4 & 1.80 & 1.80 & 1.80 \\
\hline 210 & 140 & 70 & 46.3 & 30.8 & 15.4 & 2.04 & 2.04 & 2:04 \\
\hline 330 & 220 & 110 & 62.7 & 41.8 & 20.9 & 3.0 & 3.0 & 3.0 \\
\hline 3030 & 2020 & 1010 & 137 & 91 & 46 & 25 & 25 & 25 \\
\hline $3 \times 10^{5}$ & $2 \times 10^{5}$ & $10^{5}$ & 275 & 184 & 92 & 2500 & 2500 & 2500 \\
\hline
\end{tabular}

* In each of the three blocks figures in corresponding cells go together.

ductive capital goods. Physical capital, as distinct from human capital, is composed of material goods by definition and may also be defined as the complete stock of all material goods existing at some moment. Let us, for the time being, stick to the simplification of one homogeneous material and hence exhaustible good. Let us also slightly generalize formulae (2.1) through (2.3) by replacing $A$ by $\gamma A$, where $\gamma$ may mean the fraction of the actual stock known at the moment considered.

Obviously the actual development over time of $y$ and $\dot{y}$ depends on the constants, or parameters $\delta, \gamma A$ and $t_{0}$. The meaning of $\gamma A$ has already been discussed; $\delta$ evidently represents the intensity of use of the inputs. Since for $t=t_{0}, y=1 / 2 A, t_{0}$ may be called the moment where $y$ equals the known reserve left, $1 /{ }_{2} A$; it coincides with the time at which $\dot{y}$ or production reaches its maximum.

In order to provide us with some impression of the influence of the parameters we will start from the time $t=0$ and indicate the corresponding values of $y$ and $\dot{y}$ by barred symbols $\bar{y}$ and $\overline{\dot{y}}$. As the unit of measurement of $y$ and $\dot{y}$ we choose $\overline{\dot{y}}$, meaning that production at time 0 equals 1 or 100 per cent. Since during the first part of the logistic curve it behaves approximately as an exponential function (that is, one with a constant rate of growth), we choose realistic values for $\bar{y}$ if we take 10,20 and 30 . The value of 10 corresponds with a growth rate at time 0 of about 10 per cent, the value 20 with a growth rate of about 5 per cent and 30 with a growth rate of 3.3 per cent. The latter two values are close to to-day's world, whereas 10 per cent corresponds with the quickest growing among the larger economies, namely Japan. Table I gives a numerical illustration of the influence of $\gamma A$ and the initial value $\bar{y}$ on $t_{0}$ and the maximum value of $\dot{y}$ (attained at moment $t_{0}$ ). 
From this table we see that the influence of $\gamma A$ on $t_{0}$ is relatively modest: for all cases a more than thirty-fold increase in $\gamma A$ raises $t_{0}$ ten times; the influence on $\dot{y}_{0}$ is considerably larger. Here, over the same range a more than twentyfold increase occurs. The value of initial $\bar{y}$ does not change the value of $\dot{y}_{0}$. Up to values of $\gamma A$ of a few thousand the time of maximum $\dot{y}_{0}$ is well within the period considered by the Meadows Report.

Now, assuming that in the long run the constant parameters may change, let us pose the crucial question: can we indicate the change needed in $\gamma A$ in order to keep $y$ finite, say at the level $D$ ? Looking at formula (2.3) we may simplify the solution of this problem by keeping $\lambda \gamma A$ equal to a value $c$; writing $t^{\prime}$ for $t-t_{0}$, the remaining parameter $\gamma A$ appears only once in

$$
\dot{y}=\frac{c A e^{-c t^{\prime}}}{\left(1+e^{-c t^{\prime}}\right)^{2}}
$$

of which $\lim _{t^{\prime}=\infty}=c A e^{-c t^{\prime}}$.

Only if a value $\gamma A=A_{0} e^{c t^{\prime}}$ is given to $\gamma A$ can we keep the $\lim _{t^{\prime}=\infty}$ finite; this means, however, depriving $\gamma A$ its essential character of a finite stock and hence is impossible.

Whereas production function (2.1) satisfies our desire to obtain a time pattern of $\dot{y}$ corresponding with the phenomenon of exhaustion, it also shows another feature which is out of line with the features of the majority of attempts empirically to estimate production functions and more particularly the scale effects they imply. Function (2.1) being of degree 2 in the production factors considered, namely raw material input $A-y$ and capital input $y$, deviates quite clearly from the majority of empirically estimated production functions. A closer look at this problem of which the results will be discussed below (cf. Section 8) leaves me with the impression that for most "process industries" higher scale effects than for other activities are actually found, but that these findings have seldom been given much consideration in general studies about production functions.

Thus, Z. Griliches and V. Ringstad [3], in their important study on scale effects in the Norwegian industry, exclude the most important process industries, for the understandable reason that the number of enterprises is small, but seem to forget that hence their findings are biased. Johansen, one of the authors on production functions [7] may be quoted, however, for adhering to Chenery on the possible use of "basic physical, chemical and technological principles" for the establishment of production functions. So did Limperg [12] without elaborating on it in mathematical terms. Al- 
though the material to be discussed in Section 8 supports the phenomenon of much larger scale effects with process industries, we will consider nevertheless an alternative approach in the next section.

We do so also since for large markets scale effects tend to be smaller: as soon as the market is considerably larger than the enterprise of optimal size (i. e. with minimum unit costs) there is even no scale effect. There need not exist an optimum size, however, and then scale effects remain relevant.

\section{Phase (3) of the Model: An Alternative without Scale Effects for Raw Materials and Capital}

Another approach now to be discussed assumes a production function:

$$
\dot{y}=\delta \sqrt{(A-y) y}
$$

whose only difference with (2.1) is that both production factors have now got an exponent $1 / 2$. This relationship can also be solved explicitly by

and

$$
y=A \cos ^{2}\left(-\frac{\delta t}{2}+B \beta\right)
$$

$$
\dot{y}=A \cos \left(\frac{\delta t}{2}+B \beta\right) \sin \left(\frac{\delta t}{2}+B \beta\right)
$$

where $B$ is an integration constant which together with $\beta$ is determined by the initial values of $y$ and $\dot{y}$. If we add the condition that $\dot{y}>0$, only one rising portion of (5.2) is a valid solution, to be called the goniometric alternative to our logistic curve (2.2). While there is a good deal of similarity between the two solutions, since for realistic values of the parameters (5.2) will show a very long period, the difference remains that now the exhaustion of stock $A$ will occur at a finite time distance from the starting point $\bar{y}, \overline{\dot{y}}$. The two solutions have in common, though, the existence of a finite time interval between that starting point and the moment that $y=1 / 2 \mathrm{~A}$.

Taking as an example of the complete process of solution the case where $\bar{y}=1$ and $\bar{y}=20$ (the case printed in italics in Table I) we have

yielding

$$
20=100 \cos ^{2} B \beta
$$

$$
B \beta=1.1, \text { and } 1=\delta \sqrt{80 \times 20}
$$

meaning that $\delta=1 / 40$ and the period ca. 125 years. 
Table II. Values of $t_{0}$ and $\dot{y}_{0}$ in Four Cases: Logistic, Goniometric and Quasi-logistic Solutions

\begin{tabular}{|c|c|c|c|c|c|c|c|c|}
\hline \multirow{2}{*}{$\begin{array}{l}\text { Solution } \\
(\dot{y}=1)\end{array}$} & \multicolumn{2}{|c|}{ Logistic } & \multicolumn{2}{|c|}{ Goniometric } & \multicolumn{2}{|c|}{$\begin{array}{l}\text { Quasi-logistic } \\
\delta^{\prime \prime}=0.03\end{array}$} & \multicolumn{2}{|c|}{$\delta^{\prime \prime}=0.05$} \\
\hline & $t_{0}$ & $\dot{y}_{0}$ & $t_{0}$ & $\dot{y}_{0}$ & $t_{0}$ & $\dot{y}_{0}$ & $t_{0}$ & $\dot{y}_{0}$ \\
\hline $\bar{y}=2$ & 22.1 & 1.56 & 25.6 & 1.25 & 12.6 & 1.875 & 18.4 & 2.5 \\
\hline $\bar{y}=10 \quad \gamma A=10^{3}$ & 46 & 25 & 157 & 5 & 36.2 & 18.75 & 78.4 & 25 \\
\hline $\bar{y}=10 \quad \gamma A=10^{5}$ & 92 & 2500 & 1571 & 50 & 78 & 2300 & 81 & 3333 \\
\hline $\bar{y}=30 \gamma A=210$ & 46.3 & 2.04 & 48.5 & 1.43 & 37 & 3.33 & 43 & 4.16 \\
\hline
\end{tabular}

Since for $t=t_{0}=50$, it follows that $\dot{y}_{0}(\max )=50 \delta=1.25$. It also follows that for $t=t_{0}$

$$
\cos ^{2}\left(\frac{\delta t_{0}}{2}+1.1\right)=0.5
$$

from which we derive $t_{0}=25.6$.

For the case considered the differences with Table I are not large. They do become large for more extreme cases as is shown in Table II. In such cases it will be important to make a choice (cf. Section 8).

\section{Phase (3) of the Model: Many Exhaustible Goods}

An important feature of reality is the existence of a large number of exhaustible goods, with, at this moment, widely diverging periods for which the known reserves suffice at the present rate of use. Thus, $\mathrm{McHale}$ [10] mentions exhaustion periods ranging from 19 years for lead to 570 years for aluminium, iron showing a figure of 250 . Apart from lead, zinc, tin and copper, are also mineral products whose exhaustion may be soon reached. Irrespective of the way in which these figures have been calculated they clearly diverge. Energy which at the moment according to some experts is possibly in dangerously short supply, is not so according to others. Much depends on the feasibility of nuclear fusion, of geothermal heat exploitation and of the use of solar energy. For coal $\mathrm{McHale}$ mentions a date near the year 2300 at which, at present rates of consumption, for grades considered mineable now, and for oil the year 2000. For coal further possibilities seem to be very large, however, as indicated by a value of $\eta=40$ estimated by the Paley Commission in 1951 .

In this essay I will not attempt to derive a model in which the figures for our measure of exhaustion $t_{0}$ are considered given and very different. It is an advantage of our planning approach that we can ask ourselves a much simpler question. Let the development of 
the stock of capital goods $y$ be given by (2.2) and let the production $\dot{u}$ of some other exhaustible, by analogy with (2.2), be determined by the relationship:

$$
\dot{u}=\varepsilon(B-u) y
$$

where $B-u$ is the known reserve of this exhaustible commodity, expressed in the same units as used for the calculation of $\dot{u}$. What value must we plan for $\varepsilon$, that is, how intensively must we exploit $B-u$, in order to maintain an equilibrated development over time of the production of all exhaustibles? By an equilibrated development we mean two things: (i) that (6.1) be satisfied for the given movement of $y$, and all of $B$ be finally used and (ii) that at no time $\dot{u}=0$. Trying out a solution

$$
u=\frac{B}{1+e^{-\delta A\left(t-t_{0}\right)}}
$$

we find from substitution into (6.1) that this solution satisfies (6.2) if and only if:

$$
\delta=\varepsilon .
$$

The meaning of (6.2) is that the production $\dot{u}$ reaches its maximum at the same time as $\dot{y}$ and that the production of all exhaustibles be kept proportional. In essence this means that the production and hence consumption of those with a present tendency to be exhausted soon has to be reduced. This planning proposal in fact is a research programme to find substitutes among the exhaustibles in relative abundancy for those in short supply, for instance aluminium for copper. Such a programme sets very clear priorities and that is the common-sense contribution economics can make; in fact not much of a contribution.

In reality the path defined by (6.3) cannot be attained at once; at best with some time lag and at worst not at all. In the latter case a partial "Meadows disaster" will occur.

It should be kept in mind that also $\delta$ can be changed, which corresponds with a change in $t_{0}$ (Table I) through the switching from a given rate of growth to a different one. Suppose the given initial position is $\dot{y}=1, y=20$, meaning a rate of growth of 5 per cent. It may be the case printed in italics in Table $\mathrm{I}$, which corresponds to a value 100 for $\gamma A$. With this same value we can pass on to the first column, corresponding with a growth rate of 3.3 per cent. Since the real value of $\bar{y}$ cannot be changed, but only that of $\dot{y}$, we have to change units and measure in smaller units, in such a way that $\vec{y}^{\prime}=30$ in the new units is the same quantity as $\bar{y}=20$ in the old units. This 
simultaneously changes $\gamma A^{\prime}$ into 150 as against $\gamma A=100$. From the table we then find that $t_{0}$ has now become 33.1 ; at the same time $y_{0}$ measured in the old units will have fallen to $2 / 3 \times 1.56$ or 1.04 .

\section{Phase (3) of the Model: Substitution of Exhaustibles by Non- Exhaustibles}

After all has been done to raise the known reserves of exhaustibles - as illustrated by Section 3 - the only way to maintain total consumption during the descending phase of $\dot{y}$ consists of a replacement of exhaustibles by non-exhaustibles. One might call this also the substitution of material inputs by inputs of human capital and labour, or by some types of value added (not the types consisting themselves of exhaustibles, as, for instance the yield of material capital). In its general aspects the problem has been treated very clearly by Griliches and Ringstad [4], who also developed an ingenious method to test statistically the degree of substituability between material inputs and value added as a whole. They use a regression coefficient $\mu$; a value of zero for $\mu$ corresponds to the absence of substitution, whereas a value of 1 corresponds to complete substitution possibility (an elasticity of substitution $=\infty$ ). I do not, however, agree with their interpretation of their findings. Their interpretation is that $\mu \approx 1$ for most industries; in fact the frequency distribution of $\mu$ values is:

$\begin{array}{lccc}\text { intervals } & \mu \leqq 0.4 & 0.4 \leqq \mu \leqq 0.8 & \mu>0.8 \\ \text { frequencies } & 4 & 6 & 6\end{array}$

Substitution thus has been less clear than the authors suggest. Simple empirical cases of substitution are available where out of the same exhaustible raw material finished products of different qualities can be made. The simplest way of formulating a plan for substitution (and hence research in order to raise the number of possibilities for it) is, first, to state that towards the end of the logistic curve $\dot{y}$ approximately falls by an equal percentage each year, a percentage equal to the rate of growth of production in the early phase of growth. To fix the ideas, this may be 4 per cent. With the portion of exhaustibles in total production in the neighbourhood of 0.25 , this means a fall by 1 per cent to begin with, and less later, when the portion itself is reduced. This fall in total production should then be compensated for by an additional growth in the non-exhaustible portion, making up for 0.75 of total production. This component, that is, the contri- 
bution of human capital or inventions, has been growing in developed countries over a long period and in a rather regular way. Three sources have been consulted in order to get an impression of the order of magnitude of past growth (that is, during Phase 1 mentioned in Section 2). Walters [18] determined for the United States 19091949 a generalized Cobb-Douglas production function, that is, one with a time trend $e^{\beta t}$ and admitting the possibility for scale effects (cf. Section 8), and found $1.0<\beta<1.25$. Barnett and Morse [2] found, again for the United States, an annual fall in the ratio of production (gross output) of exhaustibles to total GNP by 1.6 per cent between 1870 and 1900, 1.0 per cent between 1900 and 1930 and 1.5 per cent between 1930 and 1957. Groenveld [5] finds an annual increase of world food production between 1936 and 1959 of 1.7 per cent and Zimmermann [19] an annual increase of world real income from 1913 to 1960 by 2.7 per cent, or 1 per cent more. We may conclude that the annual contribution by non-exhaustibles has been between 1.0 and 1.6 per cent, a figure in the close neighbourhood of $\beta$ 's found for individual countries".

For the future, a similar figure would be needed, increased by the additional population growth in comparison to the past considered.

Some contribution to reduce exhaustion is made also by reusing scrapped metals. For consumption during year $t$ not only production of that year, but in addition reuse in one or another form becomes available. If the average life time of objects made from the metal concerned is $T$, the per-unit loss ratio in the process of recuperation $\lambda$, and production $\dot{x}$, the quantity available for consumption $c_{t}$ in year $t$ will be:

$$
c_{t}=\dot{x}_{t}+(1-\lambda) \dot{x}_{t-T} .
$$

The portion of $c_{t}$ represented by the second term has been estimated at 20 per cent for aluminium, 22 per cent for zinc, 34 per cent for lead, 40 per cent for copper and 60 per cent for steel. It is not clear why McHale [10] states that in the long run metals will become inexhaustibles: the total stock of copper, for instance, remains limited and one can easily imagine a standard of life for the world at large implying a higher stock.

A further contribution to the substitution of exhaustibles by nonexhaustibles may be "agrification" by which is meant replacement of

* For the United States, E. F. Denison provides figures over the period 1911-1956 (The Sources of Economic Growth in the United States, Committee for Economic Development, 1962) of 2.2 per cent per annum. 
exhaustible materials by agrarian supplies such as timber, as far as the increased timber production can be kept within an equilibrated agricultural cycle.

\section{Some Additional Empirical Information Relevant to the Model}

A central role in our approach is played by the production process of exhaustibles, which comes close to the two different concepts of primary production on the one hand and process industries on the other hand. I opted for a production function of degree 2 in the factors considered - not even including labour - or alternatives of degree 1, again leaving out labour. Both alternatives imply the assumption of considerable economies of scale and this stands at variance with the results of numerous econometric studies on production functions, usually for manufacturing industries, but sometimes for larger or other complexes, such as the economy as a whole, or agriculture.

More research will be helpful. As for the choice between the "logistic", the "quasi-logistic" and "goniometric" approach we may use - as has been done by previous students, for instance Verdoorn [17] - the property of the logistic curve that $y / y=\delta(A-y)$. In plain language this means that there is a linear relationship between the relative growth of the stock $y$ and that stock. The quasi-logistic curve can be identified by checking equations $\left(2.1^{\prime}\right)$ and $\left(2.1^{\prime \prime}\right)$. In contradistinction, the goniometric curve is characterized by a parabolic relationship between $\dot{y}^{2}$ and $y$ :

$$
\dot{y}^{2}=\delta^{2}(A-y) y=\delta^{2}\left(A y-y^{2}\right) .
$$

Here it is the absolute increases $\dot{y}$ which are taken.

One of the most comprehensive recent studies on the economies of scale has been published by Griliches and Ringstad [4]. Of the 27 industries for which the scale factor $b=\Sigma \lambda-1$, where the $\lambda$ are the exponents of the production factors in a Cobb-Douglas production function, was estimated, the highest value of $b$ was 0.158 (footwear), the median 0.075 (industrial chemicals) and the lowest -0.045 (milk products). This result is partly biased, I presume, by the omission of industries with a small number of units, which are listed in Table 3.2. Among them are: the manufacture of products of petroleum and coal; cement; ferro-alloys; iron and steel works and rolling mills, and refining of aluminium - hence some typical process industries with large and hence few units. 
Kennedy and Thirlwall [8], in a survey article for the Royal Economic Society, quote Walters [18] who, as already mentioned, for the United States 1909-1949 finds a Cobb-Douglas production function with a trend $e^{t \beta}, 1.0<\beta<1.25$ and of the degree 1.26 to 1.37 , hence $b=0.26$ to 0.37 . For agriculture Griliches [3] found, in a cross section correlation for the states of the U. S. A., $b=0.20$ to 0.28 . Richer material, more relevant for our purpose, is given by Pratten [12] and Is ard [6]. Pratten applies the subdivision of industries already discussed in Section 2 and uses as a measure the unit cost increase of a factory of half the minimum efficient scale. We can transform this figure $c$ into an approximation to $b$ by the formula $b=\frac{2 c}{1-c}$. In this way we obtain Table III.

Table III. Scale Effect for Four Categories of Industries (per cent)

Process Industries

Oil gen. purp. ref. ....... 10.5

Ethylene plants ......... 20

Sulfuric acid ............ 2.0

New dye in new plant ..... 56

Synthetic fibers ......... 10.5

Beer................. 20

Bread ............... 35

Soap and detergents ..... 5.1

Cement ............... 20

Bricks ............ 67

Steel $\ldots \ldots \ldots \ldots \ldots \ldots \ldots \ldots$ 10.5-22

Steel works
Engineering Industries

Motor cars . . . . . . 12.8

Air craft $\ldots \ldots \ldots \ldots \ldots .>50$

Bicycles ............ small

Machine tools ........ 10.5

Diesel engines $(<100 \mathrm{hp}) \cdot 8.5$

Diesel engines (large) ... 17

Design of chem. plants ... 10.5

Turbo generators ...... 10.5

Domest. elect. appl. ..... 17

Electronic cap. goods .... 17
Textile Industries

Extrusion of filament yarn .. 15

Cotton textiles .......... small

Knitting prods $\ldots \ldots \ldots \ldots \ldots$ small

Footwear ........... ca. 4
Other

Iron castings prods. . 22

Newspapers ...... $>50$

Books ........... 112

Plastic prods ....... substantial

Is ard c. s. [6], in Appendix C, provides the reader with a wealth of data on a number of chemical processes. He shows, for enterprises of different size: production, capital, labour and raw material inputs and unit costs of all inputs. We used these figures to illustrate scale effects. First we used unit costs as if they represent a single input. With one input only, the formula for scale effects $b=\sum_{i} \lambda_{i}-1$, where $\lambda_{i}$ is the exponent of production factor $i$, reduces to $b=\lambda_{1}-1$. If we compare two sizes of enterprises and indicate production in the two 
cases by $y$ and $y^{\prime}$ and factor inputs by $f$ and $f^{\prime}$, we can use the ratios $y / y^{\prime}$ and $f / f^{\prime}$ to calculate the scale effect. Writing $R$ for $\frac{y / y^{\prime}}{f / f^{\prime}}$ and $F$ for $f / f^{\prime}$ we have:

$$
R=F^{\lambda-1} \text { or } h=\lambda-1=\frac{\log R}{\log F}
$$

If there are several inputs we may calculate figures $b_{1}, b_{2}$ etc. indicating the scale effects that would have occurred if all factors had behaved as factor 1,2, ect., that is, if the inputs needed of all factors showed the same ratio $F_{1}, F_{2}$, etc. In Table IV some of the results found are shown.

Table IV. Scale Effects of Capital as Defined in Text (1) and of Total Input Costs (2) for Some Chemical Industries

\begin{tabular}{|c|c|c|}
\hline Product & (1) & (2) \\
\hline Ammonia...... & 0.35 & 0.42 \\
\hline Ammonium Nitrate & 0.38 & 0.47 \\
\hline Urea $\ldots \ldots \ldots \ldots$ & 0.24 & 0.47 \\
\hline Acetylene ... & 0.40 & 0.66 \\
\hline Chlorine Gas ......... & 2.10 & 0.33 \\
\hline Ethylene (from Ethane) & 0.42 & 0.49 \\
\hline Ethylene Dichloride ... & 0.17 & 1.53 \\
\hline Ethylene Oxide* ... & 0.31 & 0.61 \\
\hline Hydrogen Chloride. & 0.72 & 0.44 \\
\hline Hydrogen Cyanide . & 0.17 & 0.43 \\
\hline Quicklime $\ldots . . . .$. & 0.52 & 0.43 \\
\hline Sodium Cyanide & 0.20 & 0.44 \\
\hline Sulfaric Acid ... & 0.16 & 0.17 \\
\hline
\end{tabular}

* Via Chlorhydrine Process

Source: [6].

The economies of scale shown here are due to capital mainly and not to raw material inputs. A similar impression is gained from the well-known rule of thumb according to which in heavy chemical industries and steel making capital needed $K$ grows with the 0.6 th power of production $y$; inverted this may be read as $y=K^{1,67}$, that is a scale effect of 0.67 for capital alone ${ }^{1}$. The fact that economies of

1 The scale effects in chemical industries are partly due to the fact that roughly speaking production in a cube or sphere is proportional to $r^{3}$, where $r$ is the length of the cube or the radius of the sphere, whereas capital is proportional to the surface which itself is porportional to $r^{2}$. It follows that production $y=f^{1.5}$ where $f$ stands for capital. An additional reason for scale effects consists of the minimum size needed for some parts of the installation. 
scale are particular large in these types of industries is also illustrated by their frequent presence among Fortune's biggest enterprises outside the United States.

The general tendency of the figures shown supports our assumption that for process industries scale effects of the order of magnitude assumed by our two alternatives do exist.

In order to arrive at a crude first estimate of the portion $\alpha$ of exhaustibles in total production, some figures were taken from Zimmerman [19], p. 44. This portion is estimated from the ratio of the incomes from agricultural and from total production. In 1953 Zimmerman found $\alpha$ to be 0.11 for N.W. Europe, 0.25 for Latin America, 0.48 for the Middle East and 0.65 for the Far East. Taking into account, in a crude way, the total incomes of all regions of the world and the likely value of $\alpha$ according to Zimmerman's figures, and adding 0.04 for mining, I obtained $\alpha=0.25$. Some further scattered evidence seems to support this crude estimate. Active population in agriculture as given by the "Data Bank" of Unrisd [14] shows a world average of 43 per cent, and national figures ranging from 8.6 per cent for U.S.A., 33 per cent for U.S. S. R., 56.6 per cent for Brazil, 68.6 per cent for India, 69.5 per cent for Indonesia and 73.5 per cent for (old) Pakistan (all for or around 1960). Assuming that the average production (over the world) of a person in agriculture is 0.4 times the production per person in the other sectors, we obtain for the percentage of total production due to agriculture:

$$
\frac{0.4 \times 43}{57+0.4 \times 43}=23 \text { per cent. }
$$

For the Federal Republic of Germany an attempt was made to estimate the percentage of active population in the production of exhaustibles, for which we took agriculture, mining, chemical industries, mineral oil processing, production of glass, iron and steel, nonferrous metals, paper, leather and processed food; it amounts to 17 per cent in 1962.

A few figures on the elasticity of supply of exhaustibles $\eta$ have been obtained by the author from technologists; they are 2.5 to 3 for iron and 1.6 for tin. The feeling prevails that for energy resources such as oil they probably are much lower.

Finally the income elasticity of demand for exhaustibles will be well below 1 for most agricultural products, but above 1 for mineral products. For energy some figures can be derived from Schurz [13]. A cross-section analysis for per capita energy consumption in 1968 for nine countries yields $\varepsilon=1$; from changes over time for the last 
decades we may derive values ranging from 0.50 for Great Britain to 1.76 for Argentine, with the median at 0.95 for Japan. Here again a more accurate estimation will be undertaken.

\section{Some Policy Suggestions}

As already announced, the attempt made in this essay is to arrive at some planning suggestions rather than forecasts; the latter being much more difficult. Planning suggestions are easier because they take as given some desirable development and derive from it what action will have to be taken. Planning proposals are also useful, since for long-term policies the market mechanism is of doubtful help. Most raw material markets can base their prices and purchasing policies of participants on a relatively brief period only, of at most five years. Even if the expectation of high prices five years from now were almost certain, no buyer could make a profit from stocking the commodity, because of the high costs of stocking.

As also already announced, this essay does not deal with social policies, even though in my opinion these will be highly relevant; for instance redistribution of incomes, national as well as international. The main suggestions to be derived from the approach chosen are suggestions on the priorities for research.

From what was called Phase 2 of our model we may derive the conclusions that what has been called the danger spot can be postponed by a fall in population growth and of the income elasticities of demand for exhaustibles. As a matter of course the latter suggestion implies economies in the use of exhaustibles. On the other hand, a rise in the supply elasticity of exhaustibles will be favourable. Phase (2) analysis in addition suggests that some time is available to make efforts along these lines.

The analysis given of Phase (3) indicates, again as a matter of course, that research on the possibilities to replace the scarcest minerals by less scarce ones and to economize on them must have the highest priority. According to the figures given by $\mathrm{McHale}$ for the exhaustion period of some metals (cf. Section 6) in order of urgency this applies to lead, zinc, copper and tin. The tempo of exhaustion depends, inter alea, on the exact production functions, and research to establish these functions has a high priority too. Some suggestions have been made in Section 5, whereas some available figures have been summarized in Section 8. So has research on new energy sources and preferably on the use of non-exhaustible forms, such as the use of solar energy and of slowly exhaustible forms such as geothermal and nuclear fusion sources. Finally the general possi- 
bilities of substitution of exhaustible resources by new inventions which has taken place for more than a century already, should be speeded up especially if the attempts to reduce the growth of population meet with less success than hoped for on the basis of the evidence for some successful countries.

\section{References}

[1] W. J. Baumol: Economic Dynamics, New York 1951, Part I.

[2] H. J. Barnett and C. Morse: Scarcity and Growth, Baltimore 1963, p. 223.

[3] Z. Griliches: Research expenditures, education and the aggregate agricultural production function. Center for Mathematical Studies in Business and Economics, Reprint Series nr. 38, Chicago 1964.

[4] Z. Griliches and V. Ringstad: Economies of Scale and the Form of the Production Function, Amsterdam 1971.

[5] D. Groenveld: Investment for Food, Amsterdam 1961.

[6] W. Isard, E. W. Schooler, and T. Vietorisz: Industrial Complex Analysis and Regional Development: a Case Study of Refinery-PetroleumSynthetic Fiber Complexes and Puerto Rice, M. I. T. and Wiley, New York/ London 1959, Appendix C.

[7] L. Johansen: Production Functions, Amsterdam 1972.

[8] Ch. Kennedy and A. P. Thirl wall: Surveys in Applied Economics, Nr. 3, "Technical Progress", Suppl. to the Economic Journal, March 1972, p. 1.

[9] Th. Limperg: Mimeographed Courses, Amsterdam.

[10] J. McHale: World Facts and Trends, New York 1972.

[11] D. L. Meadows et al.: The Limits to Growth, New York 1972.

[12] C. F. Pratten: Economies of Scale in Manufacturing Industry, University of Cambridge, Dept. of Applied Economics, Occasional Papers: 28, Cambridge (GB) 1971.

[13] S. H. Schurz (ed.): Energy, Economic Growth and the Environment (Resources of the Future), Baltimore 1972.

[14] United Nations, Research Institute for Social Development, Compilation of Development Indicators, Geneva 1969, Indicator 50.

[15] United States News and World Report (quoted in De Nederlandse Onderneming (The Dutch Enterprise), 28 August 1970).

[16] J. J. Van Dixhoorn: Industrie en Techniek, in: Alles wat U weten wil (All you want to know, popular encyclopedia), ed. by H. van Praag, De Haan, Zeist. 
J.Tinbergen: Exhaustion and Technological Development

[17] P. J. Verdoorn: Grondslagen en techniek van de Marktanalyse (Fundamentals and Methods of Market Analysis), Leiden 1950, p. 270.

[18] A. A. Walerts: A Note on Economics of Scale, Review of Economics and Statistics XLV (1963), quoted in [8].

[19] L. J. Zimmerman: Arme en rijke landen (Poor and Rich Countries), The Hague 1964.

Address of author: Prof. Dr. mult. Jan Tinbergen, Den Haag, Haviklaan 31. The Netherlands.

It is a great honour for the editors and the redactor of the "Zeitschrift für Nationalökonomie" to publish an elaborated concept of Professor Jan Tinbergen's farewell-lecture held on November 8th 1973. We are especially glad to publish this lecture, the more so since we had the honour of publishing Professor Tinbergen's inaugural lecture in 1934. 